\title{
REMOVAL OF EOSIN STAIN FROM AQUEOUS SOLUTION BY SUNFLOWER HUSK
}

\author{
${ }^{*}$ Assalah Falih Hasan' \\ Mohammed Nsaif Abbas ${ }^{2}$ \\ 1) Environmental Engineering Department, College of Engineering, Mustansiriyah University, Baghdad, Iraq \\ 2) Environmental Engineering Department, College of Engineering, Mustansiriyah University, Baghdad, Iraq \\ 3) Environmental Engineering Department, College of Engineering, Mustansiriyah University, Baghdad, Iraq
}

Suha Anwer Ibrahim ${ }^{3}$

\begin{abstract}
This paper aims to determine the ability of sunflower husks (SH) as valuable biosorbent for removal of biological eosin $Y$ stain from aqueous solutions by and to assess the capacity of eosin stain in aqueous solutions. The SH particles dried were produced and the parameters for adsorption were analyzed including the contact time, adsorbent dose, eosin $\mathrm{Y}$ concentration, $\mathrm{pH}$ and agitation speed. The best adsorption of the eosin stain concentration between 1 to $50 \mathrm{mg} / \mathrm{L}$ was determined using batch mode adsorption, calibration curves were drawn and dye absorber amount calculated. The results demonstrate that the best eosin dye concentration had a maximum sorption ratio of $1 \mathrm{mg} / \mathrm{L}$ and the sorption ratio of $100 \%$. In comparison to alkaline $\mathrm{pH}$, sunflower husk showed better adsorption at acidic range of $\mathrm{pH}$. Throughout the whole study, the sunflower husks showed the potential to be used as an adsorbent in treatment systems of biological effluents. The result showed that the Freundlich model was found to best represent the data for eosin adsorption onto sunflower husks.
\end{abstract}

Keywords: Adsorption, eosin $Y$, sunflower husk, biological stain, pollution.

\section{Introduction}

Many non-ferrous manufacturing and chemical plants produce a large amount of dye wastewater. Due to the high concentrations of chroma in dye wastewater, it is difficult to dissolve and even dangerous, with specific employees very active in the handling of dye wastewater. Membrane isolation, ion exchange, biodegradation, chemical precipitation, and adsorption are the common treatment methods for wastewater. Adsorption is considered a very effective and inexpensive method of treatment for large industrial applications. Among them is the many effective forms. It has the properties of acid and alkali resistance, its initial production and its relatively high ratio as one of the most commonly used absorbents. There are many of source use as absorbent, recent investigations focused on effectiveness of low cost adsorbents like rice husk carbon [1], neem leaf powder [2], coconut husk [3], wheat straw [4,5], sewage sludge [6], maize cobs [7], perlite [8], wood [9], peat [10]; natural adsorbent [11], agricultural waste [12], chitin [13], waste paper [14] and rice husk [15-17] in the removal of dyes from wastewater effluent. In order to avoid the environmental hazards Eosin Y, a coal eosin dye was selected as the model anionic dye [18], and the eosin dye cationic red was used as the model pollutant in this study, The eosin dye is harmful if swallowed, inhaled, drunk, or absorbed through the skin and causes eye and skin irritation. It is widely used in textile, color solvents, inks, paints, varnishes, paper, and plastics industries because it cannot be biodegraded by traditional activated sludge

*Corresponding Author: asalafaleh@gmail.com 
processes [19]. There are other types of eosin dye, including eosin $\mathrm{B}$, which means eosin with a blue layer. This type hardly uses and has the same staining method as eosin Y, as it differs by containing a cold layer. Each type of these dyes has a special and popular use, there is also eosin ethyl and this is a variant type of eosin that has the same formula as eosin Y but substitutes the sodium by an ethyl group. This type is not used or justly redundant. And it sold as alcohol soluble eosin. Ordinary eosin $\mathrm{Y}$ is ethanol soluble at sufficient concentration to type it satisfactory as a stain from an ethanol solution. The adsorption of the eosin $y$ stain from its watery solutions by sunflower husk was investigated in this study. The impact on the batch experiments was investigated for various parameters, including $\mathrm{pH}$, agitation time, temperature, concentration and adsorbent doses.

\section{Material and Method}

\subsection{Preparation of Adsorbent and Adsorbate}

Sunflower husks feedstock (SH) were collected from market. To remove the surface adhered particles, washed the sunflower husks (SH) thoroughly by distilled water (dirt, dust, and other impurities). The washed materials were then dried $(\mathrm{SH})$ at $120^{\circ} \mathrm{C}$ to $3 \mathrm{hr}$. The samples stored in a dry plastic bottle to use. Chemical or physical treatments were not used prior for adsorption. Before adsorption trials, no other physical or chemical approaches were used. Eosin Y was bought by Ricca Chemical and used without further purification for adsorption experiments. The correct amount of eosin of $1 \mathrm{~g}$ in $100 \mathrm{ml}$ within a ratio of 50:50 of water and ethanol with magnetic rings has been dissolved to prepare $100 \mathrm{ml}$ of adsorbate solution (stock solution). Then a $0.4 \mathrm{ml}$ of acetic acid solution was added in the blending phase drop-by-drop at a concentration of $1 \mathrm{~mol} / \mathrm{L}$ to boost eosin dyes. It was then placed in a volumetric container for the creation of other dilute solutions. The dilution from the stock solution was used to prepare samples of different dye concentrations. A $250 \mathrm{~mL}$ beaker was taken at the required concentration. The stock solution is diluted by 50 times, which means that $2 \mathrm{ml}$ of stock solution is diluted to $100 \mathrm{ml}$ for the preparation of $20 \mathrm{ppm}$ of solution. Solutions of $1,5,10,20,30,40$, and $50 \mathrm{ppm}$ are typically having been taken in a variety of labeled bottles for 24 hours to homogenize. Such solutions were used to create calibration curves and to test the kinetic and balance. To determine the calibration curve of eosin $\mathrm{Y}$ satin, the calibration curve was prepared using UV spectrophotometer (Shimadzu U.V-visible, Japan.1800) at wavelength of $\lambda_{\max }=517 \mathrm{~nm}$. The percentage of dye adsorption from the aqueous solution can be calculated according to the equation:

$\% R=\frac{C_{i}-C_{e}}{C_{i}} \times 100$

Where, $\% \mathrm{R}$ is the percentage removal, $\mathrm{C}_{\mathrm{i}}$ and $\mathrm{C}_{\mathrm{e}}$ are initial and equilibrium concentrations $(\mathrm{mg} / \mathrm{L})$ respectively. The calibration curve of Eosin $Y$ stain was prepared using spectrophotometer device and it is represented by Figure 1

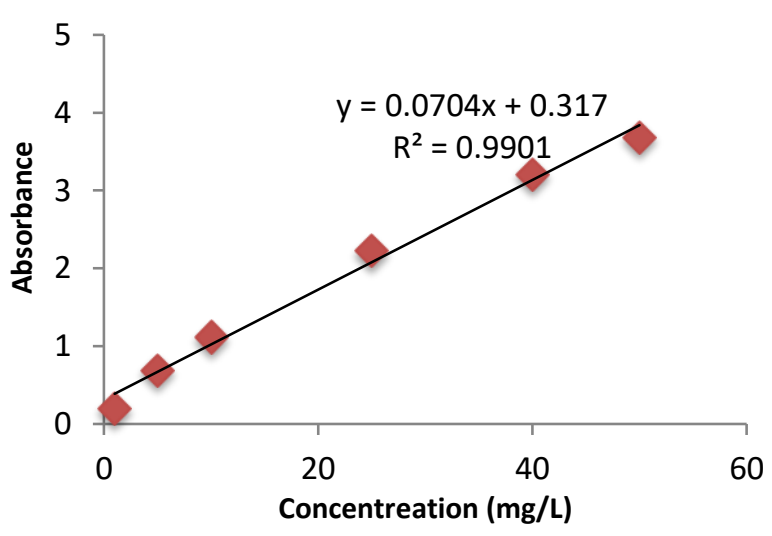

Figure 1. Calibration curve of Eosin Stain using spectrophotometer at $\lambda_{\max }=517 \mathrm{~nm}$

\subsection{Batch adsorption}

Batch experiments have shown that the solid/liquid interface adsorbing effect leads to a change in the adsorbate concentrators (i.e., the color to be studied) in the solution. Adsorption isotherms are constructed by measuring the adsorbate (farce) concentration of medium in a batch at room temperature before and after adsorption. Batch adsorption were conducted to test several parameters such as the concentration effect of 1-50 ppm, a contact time of 60-180 
min, adsorbate dose (SH) of 0.25-2 g, pH of 210 , agitation speed of 100-500 rpm. Batch adsorption experiment was performed by removal for different intervals of $60,90,120$, 130,150 , and 180 minutes from several $100 \mathrm{~mL}$ glass bottles sampling wastewater with various quantities of $0.25,0.5,1.0,1.25$, and $2.0 \mathrm{~g}$. On a flat orbital mechanical shaker, each solution was twisted and the vortex lasted 2 hours until the equilibrium was reached. The solution was then filtered (with the Gelman membrane filter of $0.45 \mu \mathrm{m})$. The UV-VIS spectrophotometry scanners (SHIMADZU) at a wavelength of 517 $\mathrm{nm}$ to eosin $\mathrm{Y}$ were used to determine filtrate absorbance. $\mathrm{pH}$ was preserved by $0.1 \mathrm{M}$ sodium hydroxide solution $(\mathrm{NaOH})$ and $0.4 \mathrm{M}$ hydrochloric acid $(\mathrm{HCl})$ before applying $\mathrm{SH}$. The quantity of adsorption at balance $\mathrm{q}_{\mathrm{e}}(\mathrm{mg} / \mathrm{g})$ was determined using the following equation [20]:

$q_{e}=\frac{C_{i}-C_{e}}{w} \times V$

Where, $\mathrm{q}_{\mathrm{e}}$ is an amount of eosin $\mathrm{Y}$ adsorbed per unit weight of $\mathrm{SH}$ in $(\mathrm{mg} / \mathrm{g})$ and $\mathrm{V}$ is the volume of solution measured by (liters) and $\mathrm{w}$ is the mass of dry sorbent $(\mathrm{SH})$ used in $(\mathrm{g})$.

\section{Results and Discussion}

\subsection{Effect of initial concentration}

The effect of initial dye concentration on the adsorption of Eosin by $\mathrm{SH}$ was studied. The range of initial dye concentration was $1-50 \mathrm{ppm}$. Figure (2) shows illustrated the removal efficiency for different initial concentration of eosin $\mathrm{Y}$ at $\mathrm{pH}=2, \mathrm{SH}$ dosage $=1.5 \mathrm{~g}$, contact time $=120 \mathrm{~min}$, and shaking speed $=400 \mathrm{rpm}$. This study was carried out at room temperature. As in the figure, it is clear that the removal of eosin $\mathrm{Y}$ from aqueous solutions decreases with an increase in dye concentration. When increased of initial dye concentration to 50 $\mathrm{mg} / \mathrm{L}$, the removal efficiency decreased to $80.84 \%$. However, the removal percentage increased to 92.1 $\%$ at initial concentration equal to $1 \mathrm{mg} / \mathrm{L}$. This result can be attributed to the fact that at a specific concentration of eosin $\mathrm{Y}$ stain, the active sites available for sunflower peel are saturated. We obtain rapid adsorption when the dye concentration is low in solution and the amount of sunflower husk is constant due to the low number of eosin dye ions in the solution.

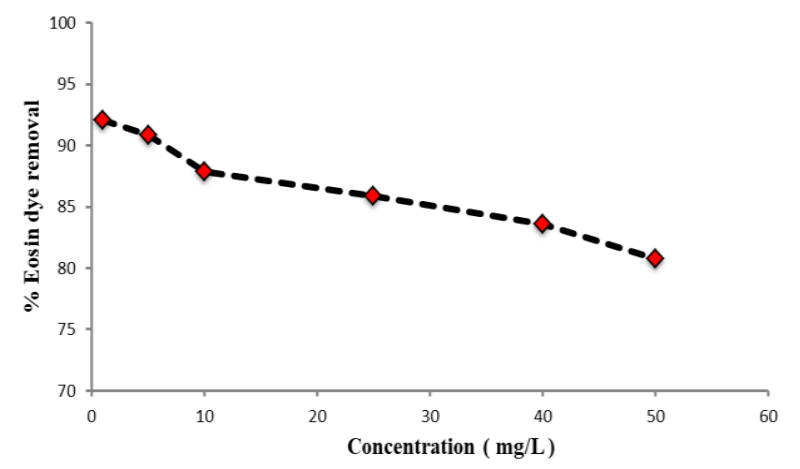

Figure 2. Effect of Initial concentration on the removal efficiency of eosin Y stain using $\mathrm{SH}$ as an adsorbent media

However, the number of eosin dye ions in solutions increases with the increase in the initial concentration, and thus we obtain a fixed amount of available active sites. Based on what was previously mentioned, the increased concentration of the initial eosin beyond the decrease in the dye removal efficiency [21] the optimum initial dye concentration was found to be equal to $1 \mathrm{mg} / \mathrm{L}$.

\subsection{Effects of the amount of adsorbent}

Effect of sunflower husk dosage on the removal of eosin dye, for selecting the best dosage of adsorbent was chosen by adding different doses of SH ranging from 0.25-2 g. However, keeping the initial concentration, agitation speed, time to shake, and best $\mathrm{pH}$ value obtained from precedent experiments constant at $1 \mathrm{mg} / \mathrm{L}, 120$ min, $400 \mathrm{rpm}$ and 2.0 respectively. According to The results effect $\mathrm{SH}$ dosage shown in figure (3) revealed that any increase in $\mathrm{SH}$ dosage, the removal efficiency of dye increased until the equilibrium was achieved. This is due to the increase in the dosage of adsorbents from the sunflower husk, which led to an increase in the surface area and the number of active sites on the adsorbent surface, thus increasing the rate of eosin $\mathrm{Y}$ dye removal. The removal efficiency increased from $68.69 \%$ at $0.25 \mathrm{~g}$ of SH to 94.44 $\%$ at $2 \mathrm{~g}$ of SH. $1.5 \mathrm{~g}$ of SH as the best dosage. Beyond a certain dosage, $2 \mathrm{~g}$, the percentage for removal of eosin dye was stabilized at $94 \%$. The reduction gradient of the concentration of the dye molecules may be the cause [22]. When the 
sunflower husk dose exceeded $1.5 \mathrm{~g}$, the adsorption efficiency of the dye insignificantly increased and that dose was considered as an optimum dose for the next experiment.

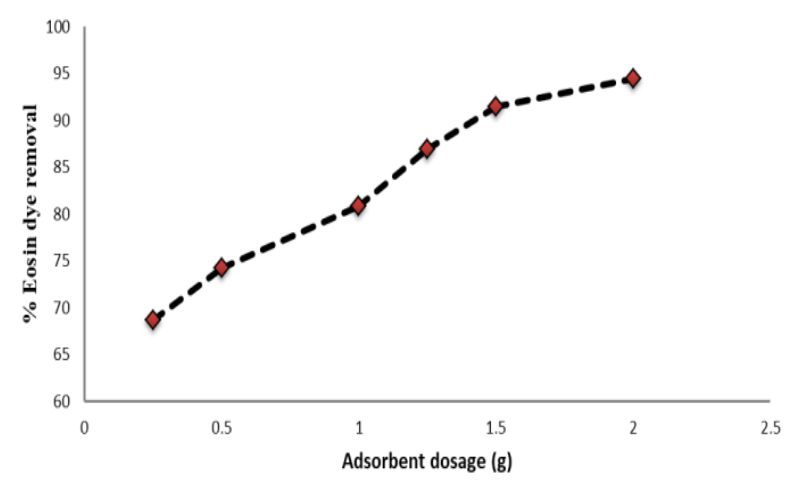

Figure 3. Effect of Adsorbent dosage on the removal efficiency of eosin Y stain using $\mathrm{SH}$ as an adsorbent media

\subsection{Effects of dye-adsorbent contact time}

The effect of contact times onto dye removal efficiency by sunflower husk was studied by varying the contact time from 90 to $210 \mathrm{~min}$ are shown in Figure (4). The $\mathrm{pH}, \mathrm{SH}$ dosages and initial concentration are kept constant at $2,1.5 \mathrm{~g}$ and $1 \mathrm{mg} / \mathrm{L}$, respectively, at room temperature. From the above figure (4), adsorption systems showed that the uptake of the eosin dye by $\mathrm{SH}$ depends largely on the contact time and initial concentration for eosin. Dye removal was rapid at initial stage (about $30 \mathrm{~min}$ ) with removal efficiency is $43.71 \%$ for eosin Y dye, After 150 min, eosin adsorption rates were slowly. The reason for this is that excess the mass transfer for eosin from its aqueous solution onto the surface of the adsorbent ( $\mathrm{SH})$ by Co which acts as a driving force. The removal of eosin $\mathrm{Y}$ increased with time to obtain equilibrium at about 150 minutes with removal efficiency of $91.62 \%$ due to a promote interaction between the surface for sunflower husk and the eosin dye molecules. However, after $150 \mathrm{~min}$ of contact time, percentage removal showed a constant/steady trend and this may be due to the slower diffusion of solute into the interior of the biosorbent [23]. As a result of a large number of available vacancies sites available, there has been an initial rapid increase in the adsorption process and over time the rate of adsorption has decreased due to the decrease in the number of active sites responsible for adsorption [24]. For further experiments, optimal contact time (135 min) was used to make sure that equilibrium was properly achieved.

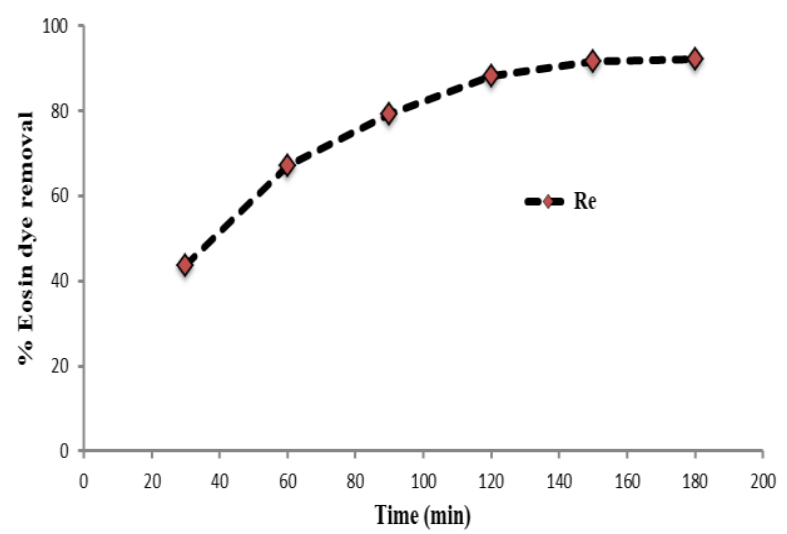

Figure 4. Effect of contact time on the removal efficiency of eosin Y stain using $\mathrm{SH}$ as an adsorbent media

\subsection{Effect of PH}

The results obtained from the $\mathrm{pH}$ parameter revealed the ability of sunflower husk in treating eosin dye effluents. The adsorbent dosage, dye initial concentration, contact time and agitation speed are fixed at $1 \mathrm{~g}$ and $1 \mathrm{mg} / \mathrm{L}, 120 \mathrm{~min}$ and $400 \mathrm{rpm}$ respectively. The solution $\mathrm{pH}$ affects the chemistry of the dye, The best $\mathrm{pH}$ for the removal of dye using sunflower husk as found in the previous experiment was equal to 2 . In the present adsorption system, the effect of $\mathrm{pH}$ was varying between 2 and 10. The adsorbed amount of eosin by $\mathrm{SH}$ was at a maximum in $\mathrm{pH}=2$ (acidic medium) and decreased sharply with increasing solution $\mathrm{pH}$ (basic medium). As shown, for eosin $\mathrm{Y}$ at $\mathrm{pH}=2$ (optimum value), the most percentage of dye removal was about $90.4 \%$ for $\mathrm{SH}$ at an initial dye concentration of $1 \mathrm{mgL}^{-1}$ and it decreased up to $\mathrm{pH}=4$. 


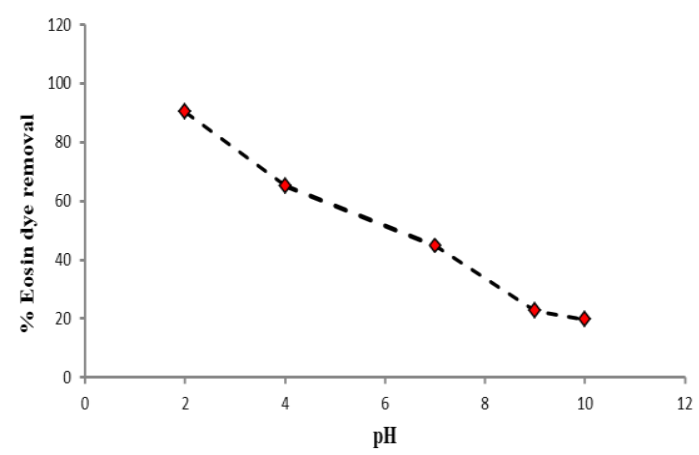

Figure 5. Effect of acidic function $(\mathrm{pH})$ on the removal efficiency of eosin $\mathrm{Y}$ stain using $\mathrm{SH}$ as an adsorbent media (Conditions: 2, $400 \mathrm{rpm}, 120 \mathrm{~min}, 1.5 \mathrm{~g}$ ).

\subsection{Effect of agitation rate}

During this section, various experiments were proceeding to study the effect of shaking speed on the adsorption of Eosin Y dye by sunflower husk. The adsorption of dye on different agitation speed was studied keeping other experimental conditions such as Eosin $\mathrm{Y}$ concentration ( $1 \mathrm{mg} / \mathrm{L})$, adsorbent dosage (1.5 $\mathrm{g}), \mathrm{pH}(2.0)$ and contact time (130 min) constant.

It appeared from figure (6), For $1 \mathrm{mg} \mathrm{L}^{-1}$ of eosin concentration with the eosin removal increase in agitation speed from 100 to 400, the percentage $\mathrm{SH}$ sorption increased from $68.18 \%$ to $85.85 \%$, It was noted that an increase in speed from 400 to $500 \mathrm{rpm}$ resulted in an increase in the percentage of removal from 85.85 to $93.43 \%$. Increasing the speed more than that does not increase the percentage of removal as a clearing plateau is obtained which displays the active points saturated and stopped adsorption. This leads to better contact between the adsorbent and the adsorbate at higher rpm [25].

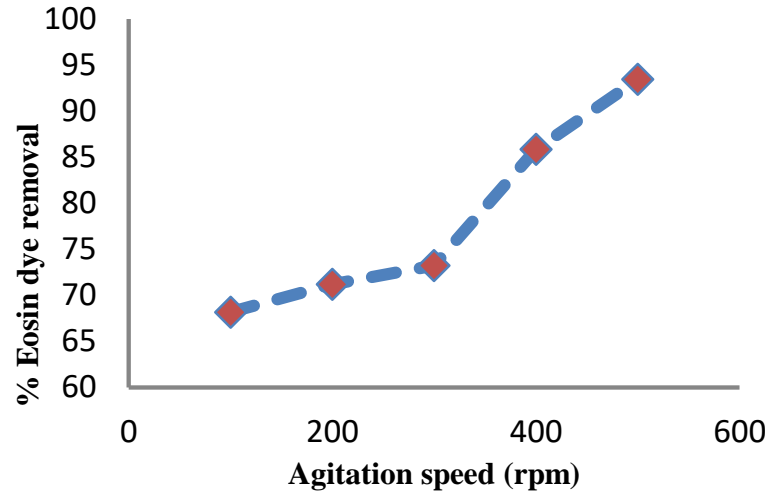

Figure 6. Effect of Agitation Rate on the Removal of Eosin by $\mathrm{SH}$ at $25^{\circ} \mathrm{C}$. (Condition: $1 \mathrm{mg} / \mathrm{L}$ Eosin concentration, 2, $130 \mathrm{~min}, 1.5 \mathrm{~g}$ ).

\section{Adsorption isotherm}

The adsorption isotherm is the equilibrium relationship between the adsorbate concentration in the fluid phase and the adsorbate concentration in the adsorbent particles at given temperature. The most common relationship between qe and Ce obtains for systems which adsorption from solution leads to the deposition of an apparent single layer or solute molecules on the surface of the solid. Occasionally, multi-molecular layers of solute may be adsorbed [26]. The limiting case of a very favorable isotherm is irreversible adsorption where the amount adsorbed is independent of concentration to very low values. An isotherm that is concave upward is called unfavorable because relatively low solid loading is obtained due to it leads to quits long mass transfer zone in the bed. From these curves it will be noted that adsorption is a specific property depending upon the nature of the adsorbate- adsorbent system. Analytical isotherm equations such as Langmuir and Freundlich isotherms are widely used for modeling adsorption data. However, these isotherms are primarily useful for simulating data collected at a fixed $\mathrm{pH}$ value and cannot be easily adapted to simulate $\mathrm{pH}$-dependent adsorption effects [27]. 
Freundlich :

$$
\log q_{e}=\log k_{f}+1 / n \log C_{e}
$$

Where $(\mathrm{qe}(\mathrm{mg} / \mathrm{g}))$ and $(\mathrm{Ce}(\mathrm{mg} / \mathrm{L}))$ as above and $(\mathrm{KF}(\mathrm{mg} / \mathrm{g})(\mathrm{L} / \mathrm{mg}) 1 / \mathrm{n})$ and $\mathrm{n}$ are Freundlich constants, $\mathrm{n}$ larger than zero [28].

Langmuir

$\frac{C e}{q e}=\frac{1}{q m b}+\frac{C e}{q m}$

Where qe adsorption capacity mg adsorbate/g adsorbent

Ce: Final concentration at equilibrium $\mathrm{mg} / \mathrm{L}$.

qm: Maximum adsorption capacity in forming complete monolayer on the surface $\mathrm{mg} / \mathrm{g}$.

b: Is coefficient related to the affinity between the adsorbate and adsorbent (L/mg)

Langmuir relationship can be linearized by plotting (1/qe) vs (1/Ce) or (Ce/qe) vs (Ce) [29].

$$
R_{l}=\frac{1}{\left(1+b \mathrm{C}_{o}\right)}
$$

Whereas, $\mathrm{C}_{\mathrm{o}}$ is the initial concentration of dye $(\mathrm{mg} / \mathrm{L})$ and $\mathrm{K}_{\mathrm{L}}(\mathrm{l} / \mathrm{mg})$ is the Langmuir adsorption constant. The adsorption of dye on the adsorbent surface is promising since $R_{1}$ is less than unity but greater than zero, irreversible $(\mathrm{RL}=0)$, linear $(\mathrm{RL}=1)$ or unfavorable $(\mathrm{RL}>1)$. It is clearly to be noticed that the adsorption isotherm of eosin was found to conform with the Freundlich model [30].

Unfavorable $(\mathrm{RL}>1)$, linear $(\mathrm{RL}=1)$, favorable $(0<\mathrm{RL}<1)$ or irreversible $(\mathrm{RL}=0)$.
Table 1. Coefficients of isotherm that applied for eosin removal by $\mathrm{SH}$.

Langmuir isotherm

Freundlich isotherm

\begin{tabular}{cccccccc}
\hline $\begin{array}{c}\mathbf{Q} \\
\max \end{array}$ & $\mathbf{b}$ & $\mathbf{K}_{\mathbf{L}}$ & $\mathbf{R}_{\mathbf{L}}$ & $\mathbf{R}^{2}$ & $\mathbf{K F}$ & $\mathbf{N}$ & $\mathbf{R}^{2}$ \\
\hline 0.234 & 0.073 & 58.47 & 0.017 & 0.925 & 3.538 & 3.854 & 0.961 \\
\hline
\end{tabular}

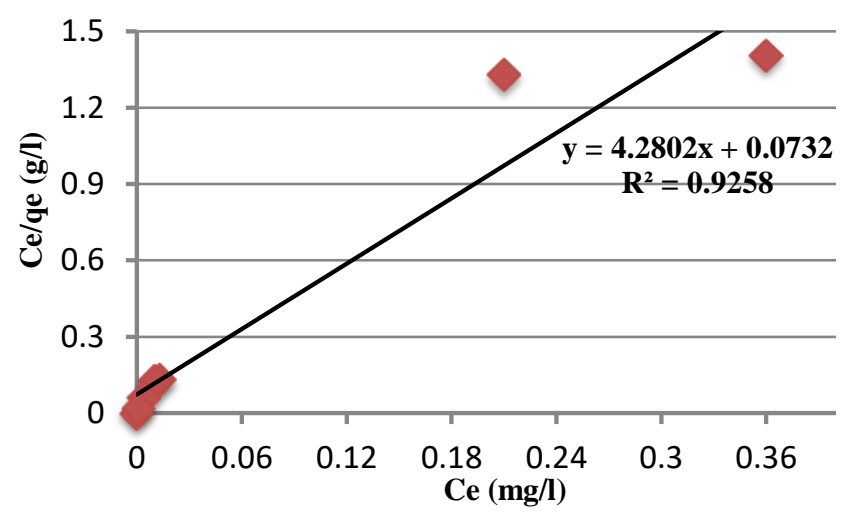

Figure 7. Langmuir Adsorption Isotherm for The Adsorption of Eosin Y Dye on Sunflower Husk.

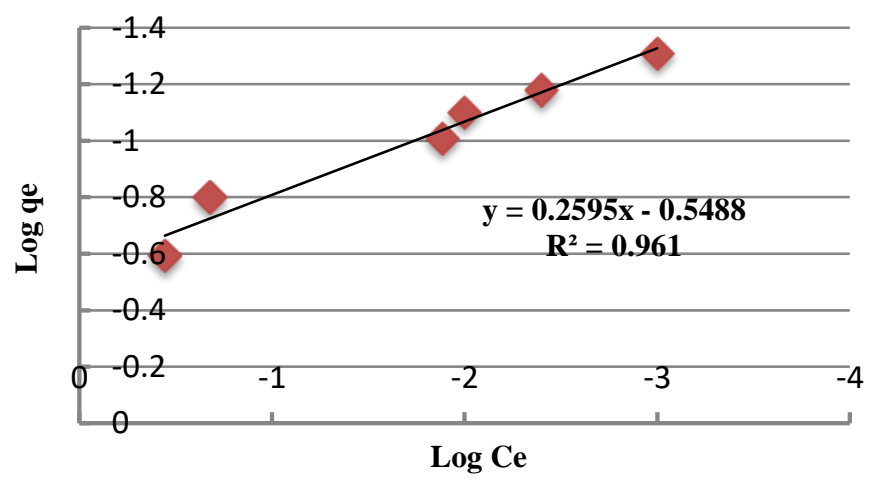

Figure 8. Freundlich Adsorption Isotherm for The Adsorption of Eosin Y Dye on Sunflower Husk.

The value of regression coefficient in case of Langmuir isotherm $\left(\mathrm{R}^{2} \geq 0.985\right)$ is closer to 1 as compared to that of Freundlich isotherm $\left(\mathrm{R}^{2} \sim\right.$ 0.960). 


\section{Characterization of SH by FT-IR and SEM}

Sunflower husk FTIR spectra before and after adsorption states of eosin y showed the peaks of $O-H$ shifted from (3464.15 to 3444.87$) \mathrm{cm}^{-1}$ is attributed to the extending vibration of the $-\mathrm{OH}$ group from $\mathrm{Al}-\mathrm{OH}$ and an intensive peak appeared at $2360.87 \mathrm{~cm}^{-1}$. There were notable changes on the spectrum after adsorption as a new band was observed at (2920-2360) $\mathrm{cm}^{-1}$ and is attributed to symmetric $C-H$ stretching. Also, one weak peaks appeared at $1739.79 \mathrm{~cm}^{-1}$, which were assigned to $C=O$ bands variation. The peak band of $1627 \mathrm{~cm}^{-1}$, which indicates the presence of an aldehyde and ketone $C O$ band. Furthermore, at $1512 \mathrm{~cm}^{-1}$ the sharp peak indicates the presence of primary amides and implies $C-N$ retention and $N-H$ curvature. The symmetrical - NO2 band extension can also be attributed to the flat top at $1512 \mathrm{~cm}^{-1}$. The peak of $\left(1381.03 \mathrm{~cm}^{-1}\right)$ represents $\mathrm{P}-\mathrm{OH}$ stretching. The peaks around $\left(779.24 \mathrm{~cm}^{-1}\right)$, corresponds to $\mathrm{Si}-\mathrm{H}$ groups [31].

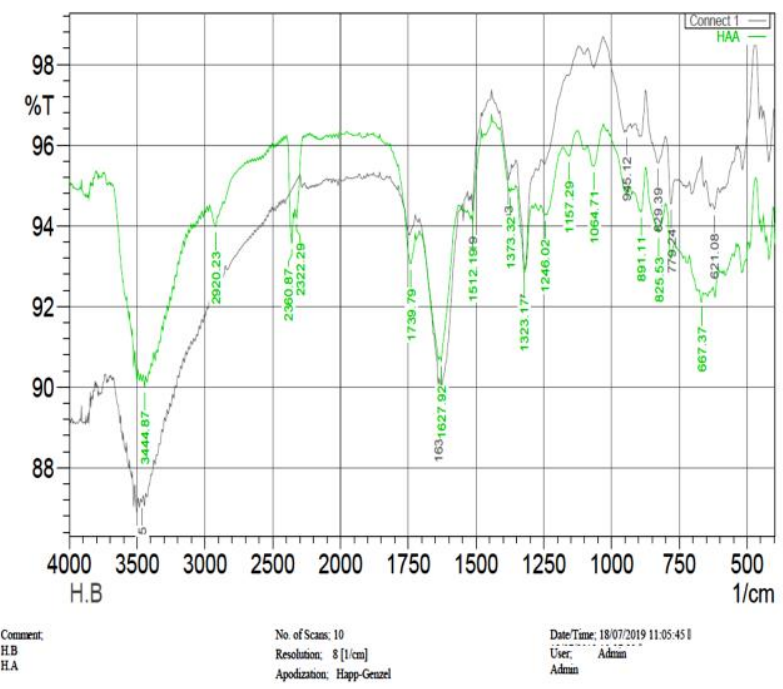

Figure 9. FT-IR spectrum for Sunflower Husk (A) Before Adsorption and (B) After Adsorption

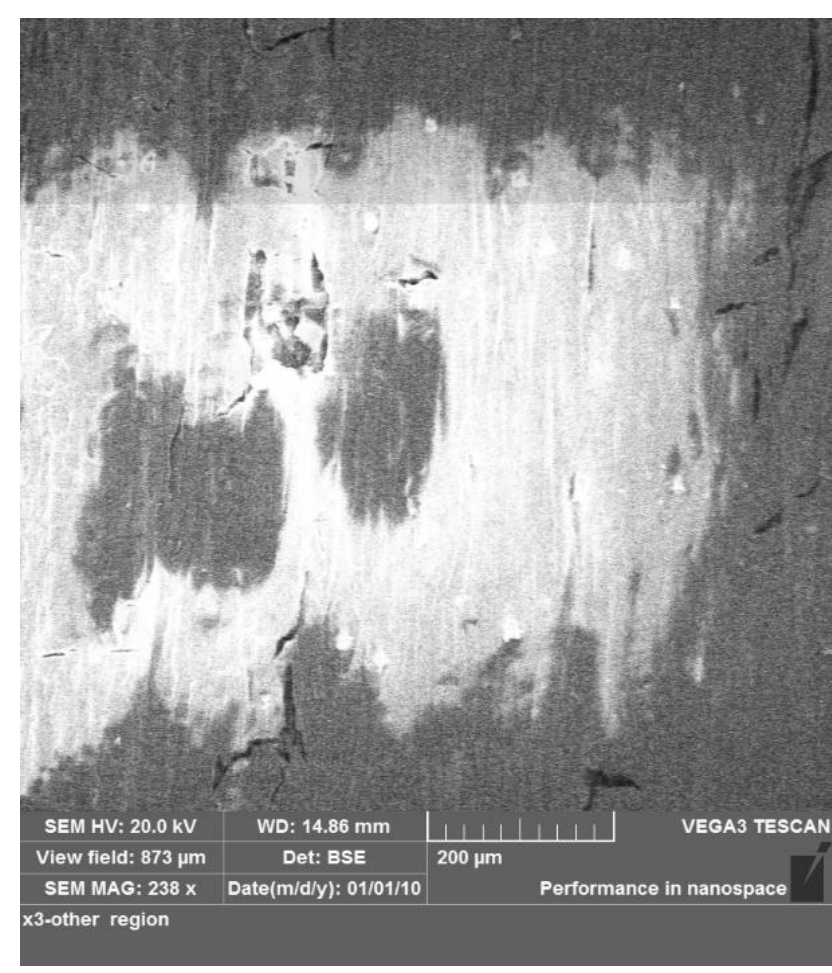

(A)

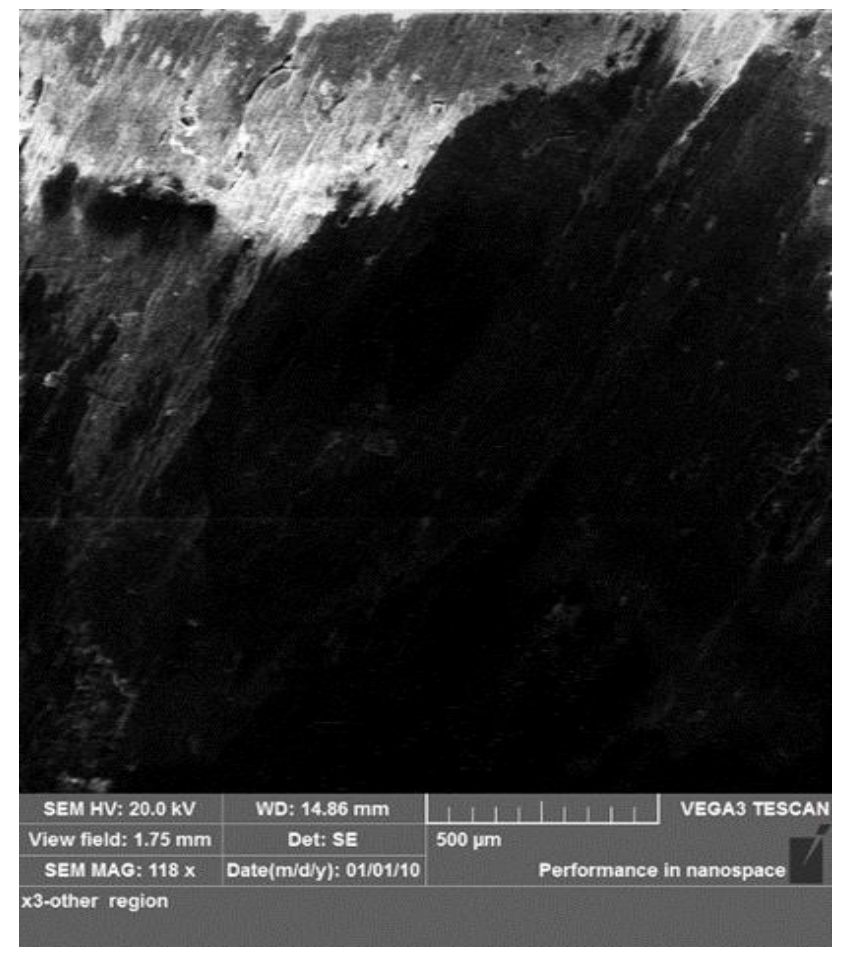

(B)

Figure 10. Scanning Electron Microscopy of Sunflower Husk: (A) Before adsorption (B) Eosin adsorption 


\section{Conclusions}

Simple equipment, easiness of service, low cost, lower time and reduced charging are characterized by adsorption. Aquatic solution dye removal was shown by analyzing water quality parameters like $\mathrm{pH}$, pre-and posttreatment values. The results of this study are consistent with the fact that sunflower husk is an effective adsorbent for the removal of eosin color. Utilizing an adsorbent weight, contact time, $\mathrm{pH}$, adsorbate concentration, UV-and IR spectrums recorded before and after the adsorption, the dyes have undergone some structural changes during procedures, thereby can be optimized for adsorption efficiency. It can be also concluded the use of the inexpensive $\mathrm{SH}$ adsorbent to remove eosin color from the aqueous solution. Furthermore, the sunflower husk obtained to study sunflower husk efficiency color adsorption that displays that $\mathrm{SH}$ particles are either engulfed (or adsorbed) on the surface of dye molecules. The adsorption Eosin $\mathrm{Y}$ dye on SH showed a better agreement with Freundlich model compared that of Langmuir isotherm.

\section{Acknowledgements}

The authors would like to thank Mustansiriyah University/college of engineering Baghdad-Iraq for its support in the present work and the Laboratory staff in the College of Engineering for their support and help through the period of the experiments.

\section{Conflict of interest}

There are no conflicts to declare.

\section{References}

1. Verma V. K. and Mishra A. K., (2010), "kinetic and isotherm modeling of adsorption of dyes onto rice husk carbon", Global NEST Journal, Volume 12, No. 2, pp: 190-196. https://doi.org/10.1016/0043-

1354(85)90145-9

2. khatod I. and Thakur L. S. (2011), "Adsorption of malachite green dye from aqueoussolution on neem leaf powder", EM International, Publishers of Quality International Journals, Volume 30, Issue 4, pp: 469-472.

3. Etim U. J., Umoren S. A. and Eduok U. M., (2016), "Coconut coir dust as a low cost adsorbent for the removal of cationic dye from aqueous solution", Journal of Saudi Chemical Society, Volume 20, pp: S67-S76. https://doi.org/10.1016/j.jscs.2012.09.01 4

4. Robinson T., Chandaran B. and Nigam P., (2002), "Removal of dyes from a synthetic dye effluent by biosorption on wheat straw", Water Research, Volume 36, pp: 2830-2842.

5. Verma V. K. and Mishra A. K., (2006), "Removal of dyes by the wheat straw carbon", Ecology environment and conservation, Volume 12, pp: 755-757.

6. Otero M., Rozada M., Calvo L. F., Garcia A. I. and Moran A., (2003), "Kinetic and Equilibrium modeling of methylene blue from solution by adsorbent materials produced from sewage sludges, Biochemical Engineering Journal, Volume 15, Issue 1, pp: 59-68, January. https://doi.org/10.1016/S1369703X(02)00177-8

7. Singh J. and Kaur G. (2013), "Freundlich, Langmuir adsorption isotherms and kinetics for the removal of malachite green from aqueous solutions using agricultural waste rice straw", International Journal Of Environmental Sciences, Volume 4, Issue 3, No 3. https://doi.org/10.6088/ijes.2013040300 004

8. Dogan M., Alkan M. and Onganer Y., (2000), "Adsorption of methylene blue from aqueous solution onto perlite", 
Water Air \& Soil Pollution, Volume 120, pp: 229-248.

9. Poots V. J. P., Mckay G. and Healy J. J., (1978), "Removal of basic dye from effluent using wood as an adsorbent", Water Pollution Control Federation, Volume 50, pp: 926-931.

10. Namasivayam C. and Kanchana N., (1993), "Removal of Congo red from aqueous solution by waste banana pith", Pertanika Journal of Science \& Technology (JST), Volume 1, pp: 33-39.

11. Bayat B. (2002), "Combined Removal of Zinc (II) and Cadmium (II) from Aqueous Solutions by Adsorption onto HighCalcium Turkish Fly Ash", Water, Air and Soil Pollution, Volume 136, pp: 69-92. https://doi.org/10.1023/A:1015296032528

12. Gupta V. K. and Suhas (2009), "Application of Low-Cost Adsorbents for Dye Removal--A Review", Journal of Environmental Management, Volume 90, Issue 8, pp: 2313-2342.

https://doi.org/10.1016/j.jenvman.2008.11.0 17

13. Annadurai G., Juang R. S., Yen P. S. and Lee D. J., (2003), "Use of thermally treated waste biological sludge as dye absorbent", Advances in Environmental Research, Volume 7,Issue 3, pp: 739-744. https://doi.org/10.1016/S10930191(02)00044-8

14. Besma M., Nisreen S. and Tamarah T., (2018), "Using Paper Waste as Adsorbent for Methyl Violet dye removal from waste water". Journal of Engineering and Sustainable Development, Volume 22, No. 1.

15. Kadirvelu K., Palanival M., Kalpana R. and Rajeswari S., (2000), "Activated carbon from an agricultural by-product, for the treatment of dyeing industry wastewater", Bioresource Technology, Volume 74, Issue 3, pp: 263-265.

https://doi.org/10.1016/S09608524(00)00013-4

16. Feng Q., Lin Q., Gong F., Sugita S. and Shoya M., (2004), "Adsorption of lead and mercury by rice husk ash", Journal of colloid and interface science, Volume 278, Issue 1, pp: 1-8.

https://doi.org/10.1016/j.jcis.2004.05.03 0

17. Chuah T. G., Jumasiah A., Azni I., Katayon S. and Choong S. T., (2005), "Rice husk as a potentially low-cost biosorbent for heavy metal and dye removal: an overview", Desalination, Volume 175, Issue 3, pp: 305316.

https://doi.org/10.1016/j.desal.2004.10.014

18. Chatterjee S., Chatterjee S., Chatterjee B. P., Das A. R. and Guha A. K., (2005), "Adsorption of a model anionic dye, eosin $\mathrm{Y}$, from aqueous solution by chitosan hydrobeads", Journal of colloid and interface science, Volume 288, Issue 1, pp: 30-35.

https://doi.org/10.1016/j.jcis.2005.02.055

19. Zhou M. and He J., (2008) Degradation of cationic red X-GRL by electrochemical oxidation on modified $\mathrm{PbO}_{2}$ electrode, Journal of hazardous materials, Volume 153, Issues 1-2, pp: 357-363. https://doi.org/10.1016/j.jhazmat.2007.08.0 56

20. Li Z., Wang G, Zhai W, He C, Li Q. and Guo P., (2018), "Methylene blue adsorption solution by loofah sponge-based porous carbons", Colloids and Surfaces A Physicochem Engineer Aspects, Volume 538, pp: 28-35.

https://doi.org/10.1016/j.colsurfa.2017.10.0 46

21. Khataee A. R., Ayazloo M., and Pourhassan M., (2009), "Biological decolorization of C.I. Basic Green 4 solution by Chlorella sp.: effect of operational parameters", China science journal of Appplied Environmental Biology, Volume 15, pp: 110-114.

22. Zhu B., Fan T., and Zhang D., (2008), "Adsorption of copper ions from aqueous solution by citric acid modified soybean straw", Journal of Hazardous Materials, Volume 153, pp: 300-8.

https://doi.org/10.1016/j.jhazmat.2007.08.0 50. 
23. Bazrchi S., Bahram M., and Nouri S., (2018), "Equilibrium and Kinetic Studies on the Removal of Acid Red-14 from Aqueous Solutions Using PSMA" Iranian Journal of Science and Technology, Iran, Volume 42, pp: 203-208.

24. Kumar K. V., (2006), “Comparative analysis of linear and non-linear method of estimating the sorption isotherm parameters for malachite green onto activated carbon," Journal of Hazardous Materials, Volume 136, Issue 2, No. 2, pp: 197-202.

https://doi.org/10.1016/j.jhazmat.2005.09.0 18

25. Demirbas A., (2003), "Biodiesel Fuels from Vegetable Oils via Catalytic and NonCatalytic Supercritical Alcohol Transesterifications and Other Methods: A Survey". Energy Conversion and Management, Volume 44, pp: 2093-2109.

https://doi.org/10.1016/S01968904(02)00234-0

26. Ahmed, K. W., (2006), "Removal of multipollutants from wastewater by adsorption method," Doctoral dissertation, Ph. D. Thesis, University of Baghdad.

27. Jeppu, G. P., and Clement, T. P., (2012), “A modified Langmuir-Freundlich isotherm model for simulating $\mathrm{pH}$-dependent adsorption effects", Journal of contaminant hydrology, Volume 129, pp: 46-53.

https://doi.org/10.1016/j.jconhyd.2011.12.0 01

28. Boparai H.K., Joseph M., and O'Carroll D.M., (2011), "Kinetics and thermodynamics of cadmium ion removal by adsorption onto nano zerovalent iron particles", Journal of hazardous materials, Volume 186, No. 1, pp: 458-465. https://doi.org/10.1016/j.jhazmat.2010.11.0 29

29. Adeogun A., Idowu M., Ofudje A., Kareem S., and Ahmed S., (2013), "Comparative biosorption of $\mathrm{Mn}$ (II) and $\mathrm{Pb}$ (II) ions on raw and oxalic acid modified maize husk: kinetic, thermodynamic and isothermal studies", Appl. Water Sci., Volume 3, No. 1, pp: 167-179.

30. Deniz F., and Saugideger S. D., (2010), "Investigation of adsorption characteristics of basic red 46 onto gypsum: equilibrium, kinetic and thermodynamic studies", Desalination, Volume 262, No. 1-3, pp: 161-165.

\section{https://doi.org/10.1016/j.desal.2010.05.062}

31. Safa, Y., and Bhatti, H. N., (2011), "Kinetic and thermodynamic modeling for the removal of Direct Red-31 and Direct Orange-26 dyes from aqueous solutions by rice husk.", Desalination, Volume 272, No. 1-3, $\quad$ pp:

313-322. https://doi.org/10.1016/j.desal.2011.01.040 